\title{
Intergenerational Relationships and Communication among the Rural Aged in Malaysia
}

\author{
Rahimah Abdul Aziz ${ }^{1} \&$ Fatimah Yusooff ${ }^{2}$ \\ ${ }^{1}$ School of Social, Development and the Environmental Studies, Faculty of Social Sciences and Humanities, \\ Universiti Kebangsaan Malaysia, Bangi, Malaysia \\ 2 School of Psychology snd Human Development, Faculty of Social Sciences and Humanities, Universiti \\ Kebangsaan Malaysia, Bangi, Malaysia \\ Correspondence: Rahimah Abdul Aziz, School of Social, Development and the Environmental Studies, Faculty \\ of Social Sciences and Humanities, Universiti Kebangsaan Malaysia, 43600 Bangi, Selangor, Malaysia. Tel: \\ 60-3-8921-5228. E-mail: ikra@ukm.my
}

$\begin{array}{lr}\text { Received: December 28, } 2011 \quad \text { Accepted: January 30, 2012 } & \text { Published: May 1, } 2012 \\ \text { doi:10.5539/ass.v8n6p184 } & \text { URL: http://dx.doi.org/10.5539/ass.v8n6p184 }\end{array}$

The research is financed by the Univers Foundation, Japan. We would like to document our deepest appreciation to the Foundation. Also, comments and suggestions from discussants were helpful in revising the work.

\begin{abstract}
In Malaysia the family has been the main institution caring for the aged. However, the processes of development, directly or indirectly, have impacted the size, functions and structure of the family unit, which subsequently impacted the family intergenerational relationships and communication. This study is about the intergenerational relationships and communication specifically among the rural aged with their family members. The main objective is to further understand the relationship of the aged with those around them and its contribution to productive and quality ageing process. Survey was the main method used in the study and was conducted among 200 older persons residing in the rural area of mukim Sungai Petani, in the district of Kuala Muda, Kedah, Malaysia. A total of 186 co-residing adult children were also interviewed. The study shows that the intergenerational relationship is still stable and harmonious. The study also shows that the family structure in the area is mainly extended rather than nuclear with the family members exchanging mutual support. In fact, family and kinship network have remain important support network for the families. Generally, the children show positive and responsible attitudes towards their parents. This is in line with Malaysian culture that places importance on good and close relationships between generations.
\end{abstract}

Keywords: rural aged, intergenerational relationships, communication, family, Malaysia

\section{Introduction}

Family is regarded as a source of help and support for the elderly (Note 1). However, the quality and frequency of the support that they receive are very much dependent on the shape and quality of the relationship that exists between the elderly and the family members of various generations, particularly the second generation. The processes of modernisation, development and migration, directly or indirectly, have impacted the size, functions and structure of the family unit, which subsequently impacted the family intergenerational relationships and communication. Malaysian families are also faced with this situation.

\section{Ageing Trend in Malaysia and Changing Family Structure}

The impact of development processes has resulted in an increase in the number of the aged in Malaysia's population due to decreasing birth rate and mortality rate. Using age 60 years and above to define the aged, it is estimated that at a growth rate of $4.4 \%$ per annum the total aged population will reach approximately 3.21 million by year 2020, that is $9.5 \%$ of the total population (Dept. of Statistics, Malaysia 1998). As shown in Table 1 the percentage of the aged in Malaysia has increased from $4.8 \%$ in 1960 to $5.7 \%$ in 1980 and to $6.2 \%$ in year 
2000. Generally, while the aged population shows an increasing trend the population of the young on the other hand is decreasing. This is a clear indication of an ageing population.

Table 1. Malaysia: ageing trend (1960-2020)

\begin{tabular}{lccc}
\hline Year & $\begin{array}{c}\text { No. of aged } \\
\text { ('000) }\end{array}$ & $\begin{array}{c}\text { Percentage of total } \\
\text { population }\end{array}$ & $\begin{array}{c}\text { Growth rate of aged } \\
\text { population }\end{array}$ \\
\hline $1960^{*}$ & 386.6 & 4.8 & - \\
1970 & 546.1 & 5.2 & 3.5 \\
1980 & 745.2 & 5.7 & 3.1 \\
1991 & 1032.3 & 5.9 & 3.0 \\
2000 & 1451.6 & 6.2 & 3.5 \\
$2010^{* *}$ & 2076.1 & 7.3 & 3.8 \\
$2020 * *$ & 3209.8 & 9.5 & 4.4 \\
\hline
\end{tabular}

* Estimate

** Projection

Source: Dept. of Statistics, Malaysia 1998, 2001.

Rural-urban population distribution shows that despite the increasing rate of urbanization it is interesting to note that the aged population in the rural sector is still relatively higher than in the urban sector. In 1970 the urban aged population is only $26.9 \%$ compared to $73.1 \%$ in the rural sector (Table 2). However, in 1991 the urban population of the aged has increased to $45.6 \%$ and decreased to $54.4 \%$ in the rural sector. The year 2000 saw a continuing increasing trend of the aged population in the urban sector $(54.1 \%)$ compared to the rural sector where the aged population continue to decrease (Dept. of Statistics, Malaysia 1998, 2001) (Note 2).

Table 2. Malaysia: percentage rural-urban distribution of the aged (1970, 1980 and 1991)

\begin{tabular}{cccc}
\hline Year & Urban & Rural & Total \\
& \multicolumn{4}{c}{ Percentage distribution by stratum } \\
\hline 1970 & 26.9 & 73.1 & 100.0 \\
1980 & 32.9 & 67.1 & 100.0 \\
1991 & 45.6 & 54.4 & 100.0 \\
2000 & 54.1 & 45.9 & 100.0 \\
\hline
\end{tabular}

Source: Dept. of Statistics, Malaysia. 1998, 2001.

In terms of ethnic groups, majority of the ethnic Malays have traditionally resided in the rural areas. However, socio-economic transformation that had taken place in the country, especially since the 1970 s, has resulted in their rural-urban migration, although the older generation tended to remain behind. The proportion of the Chinese elderly remains high in both the rural and urban areas, while a higher percentage of the Indians elderly is found in the urban rather than the rural areas (Dept. of Statistics, Malaysia 1998).

With regard the family structure, two demographical trends have led to its significant change, namely the increasing life expectancy and decreasing fertility rate. Consequently, it has been generally regarded that with the elderly living longer and the population of the young (especially those aged 20 years and below) growing smaller, the family structure has changed from the shape of a pyramid to that of the 'beanpole' (Bengston, Rosenthal \& Burton, 1990). This means that the family structure has changed from having small number of older persons at the top and big number of children and an even bigger number of grandchildren at the bottom to a structure where there are more generations in a family but with smaller number for each successive generation. Such a structure means that longer co-survivorship between generations (Bengston 1996) would have implications on all generations especially in terms of relationships, roles and functions. Both adult children and adult grandchildren of the same age cohort now contribute to the support extended to the aged. However, while this may reflect the general situation of the developed countries, it may not be the case for developing countries where the birth rate still remains high while life expectancy is also on the increase. This means that the pyramid-shaped family structure still remains the norm, perhaps for sometime to come. 


\section{Family Care and Support for the Aged as Part of Socio-Economic Well Being}

In general it can be said that many studies have been conducted on parent-child relationships especially in families with young children. However, only recently have studies on intergenerational relations have been focused, that is specifically relationships between parents and adult children. This is because adult children are one of the closest sources of support - social, psychological and economic -for the elderly. Intergenerational relationships generally involve emotional ties and more instrumental forms of support such as financial resources or child care. Studies have found that the aged still have significant role to play in the family besides being both givers and receivers of support in their relationship with their children. This mutual support between them and the adult children contributes to their life satisfaction (Kim \& Kim 2003; Kim, Hisata, Kai \& Lee 2000; Vebrugge \& Chan 2008) and subsequently to their well being and quality of life. Social support that is extended or given can be categorised in terms of types and frequency, quality and quantity, instrumental and emotional as well as formal and informal. In many of the studies that had been conducted it had been reported that most parents and adult children described their relationships with their children or parents as meaningful and supportive. However, some studies also found troubled relationships that subsequently become a source of psychological distress for both parents and children (Pillemer, Suitor, Mueller-Johnson, Sechrist \& Heidorn 2006). Also, the frequency and types of support given can also be determined by geographical distance. In fact distance by far is the strongest predictor of contact (Uhlenberg \& Hammill 1998).

In Malaysia, like in many other Asian countries the family has been the main institution caring for the aged. Their younger members, out of their sense of duty and filial piety, care for elderly family members. Family care is usually home based and the family provide a variety of assistance and care to its aged members to ensure their socio-economic well being. Economic well being includes providing food, clothing and shelter; and financial assistance. While social well being includes family care, housekeeping, socio-emotional support; and personal care. This range of care, which is provided round the clock, forms a part of everyday family interaction and is addressed by the caregiver on an individual basis. Nonetheless, the extended family structure, which makes such care giving possible is gradually disintegrating and changing towards the nuclear family system. This transformation is due to the modernisation process, rapid development, urbanisation, rural-urban migration etc. With these changes there is no longer any guarantee that the family will continue to be able to maintain its traditional role of directly caring for their aged relatives.

Also, with longer life expectancy and higher cost of living, it would become increasingly burdensome for the families to provide financial support and health care needs of their aged relatives. Added to that, families have limitations in their capacity to care. Limitations are in the form of knowledge, skill, financial and availability of family members to provide the care. Thus, many senior citizens are left to fend for themselves at a time when they most need care, support and companionship. While it is acknowledged that the family is still the key unit through which aged-care is given, however family institutions face tremendous challenges. Even when external care institutions and agencies have proved useful in providing care for the aged in certain aspects, they are only bridging the gap created by the increasingly diminishing role of the family.

\section{The Study}

As mentioned earlier the changing lifestyle has directly or indirectly affected the quality and frequencies of the intergenerational relationship and communication. This in turn influences the types and level of support given by the family members (whether spouse, children, siblings, grandchildren and other relatives) to the aged. This means that if the relationship is detached and distant it would be difficult for the aged to get support and assistance even from their own immediate family members. They would then have to depend on other sources whether formal (government) or informal (friends, neighbours, etc.).

Regarding the intergenerational relationship and communication of the rural aged a study was conducted to further understand the relationship of the aged with those around them and its contribution to productive and quality ageing process. It is also to see whether there still exists a sense of mutual obligations and interests among family members to ensure continuous support and well being. Finally, the research is to look into the relationship of the rural aged and their social circle, especially within the community they live in. 


\section{Method}

\subsection{Samples}

Using both the qualitative and quantitative approaches, the study was conducted in two phases. For the first phase, a survey was conducted in the months of March to May 2008, to collect data from among those aged 60 years and above (Note 3). A structured questionnaire was used to capture the appropriate data. The instrument was pre-tested for its appropriateness and reliability. Besides the aged, their adult children or relatives who co-reside with them were also surveyed to understand their position relating to living with their older parents, caring for them and their on-going relationships that have enabled them to continue to care for the aged. Using the non-probability sampling technique a total of 200 older persons were chosen from households with at least one aged person residing. Besides the aged, a total of 186 adults second generation co-residing with them were also surveyed. The non-probability sampling technique was used because the writers wanted to establish specific criteria to be used to select the respondents. In this case the respondents were to be at least 60 years old. They could be residing with other members of the family or living alone. Furthermore there was no testing of hypotheses. Rather, questions were asked in a particular direction until things could be explained (Robson 1993).

In the second phase a total of ten older persons were further interviewed. The face-to-face in-depth interview was adopted to gain a better insight of the issues and challenges generally faced by older persons residing in the rural area, that otherwise may not be captured through the quantitative method.

\subsection{Site}

The study was conducted in the rural sector of mukim (Note 4) Sungai Petani that is one of the fourteen mukim of the Kuala Muda district (Map 3). The name Sungai Petani has its roots from 'sungai' meaning 'river' and 'petani' meaning 'farmer'. Thus, Sungai Petani literally means "Farmer's River", due to the huge concentration of paddy fields and farmers in the state. The district Kuala Muda in turn is among the eleven districts of the state of Kedah in the north of Peninsular Malaysia (Maps $1 \&$ 2). Kedah state has a population of 1.9 million with predominantly Malay population (75.4\%). Thus, although Kedah state has a multiethnic population, it is a Malay Muslim heartland. The predominantly Malay population of the state are relatively conservative, religious and practices traditional values. Being one of the mukim in the Kedah state, mukim Sungai Petani also has a multiethnic population totalling 143,523 (Population Census 2000). However, the Malay ethnic group predominantly populates the rural area. Based on the 2000 population census there is a total of 7758 older persons aged 60 years and above residing in mukim Sungai Petani (Population Census 2000). This is about $35.4 \%$ of the total aged residing in the district of Kuala Muda (aged population 21894) compared to the state of Kedah over 60 years old population of 125,286 (6.2\%). The majority of the population in the rural sector of the mukim are involved in traditional agricultural activities, especially padi planting.

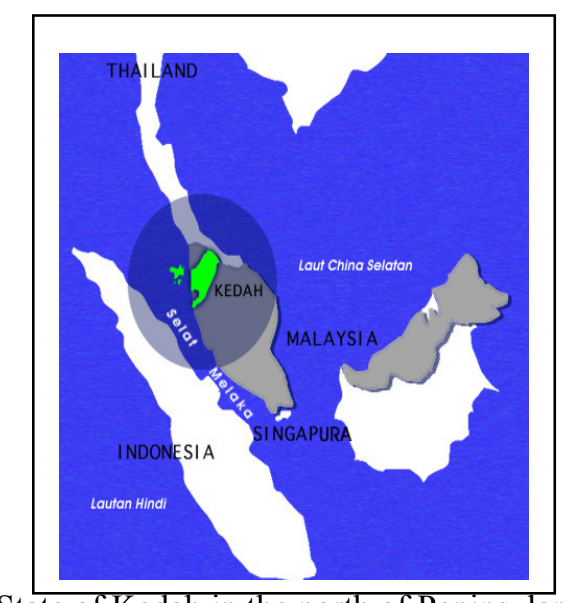

Map 1. State of Kedah in the north of Peninsular Malaysia

Map 1

http://images.search.yahoo.com/search/imafes:ylt=A0S0206WOMxJzWOBmxKJzbkF?p=peta + malaysia\&fr $=\mathrm{slv}$ 8-msgr\&ei $=$ utf- $88 \mathrm{x}=$ wrt 


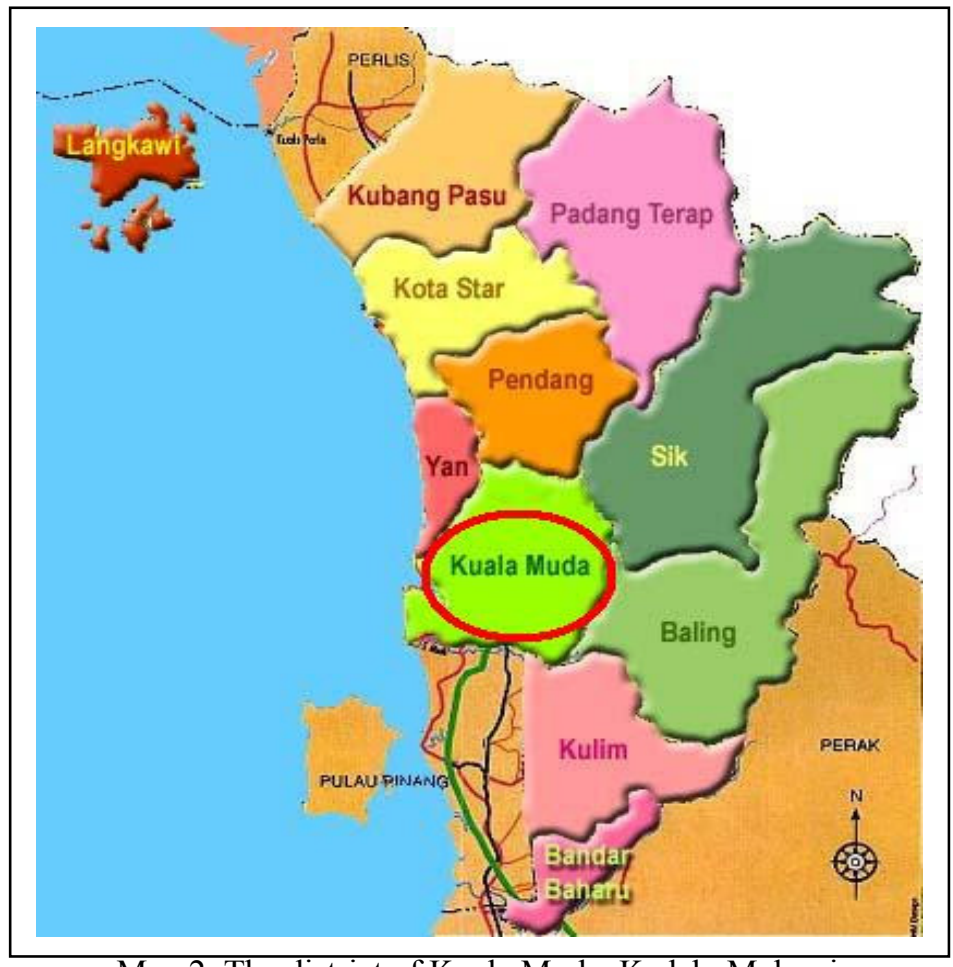

Map 2. The district of Kuala Muda, Kedah, Malaysia

Map 2 = http://images.google.com/images?gbv $=2 \& \mathrm{hl}=$ en $\& \mathrm{sa}=1 \& \mathrm{q}=$ peta + daerah + kuala + muda

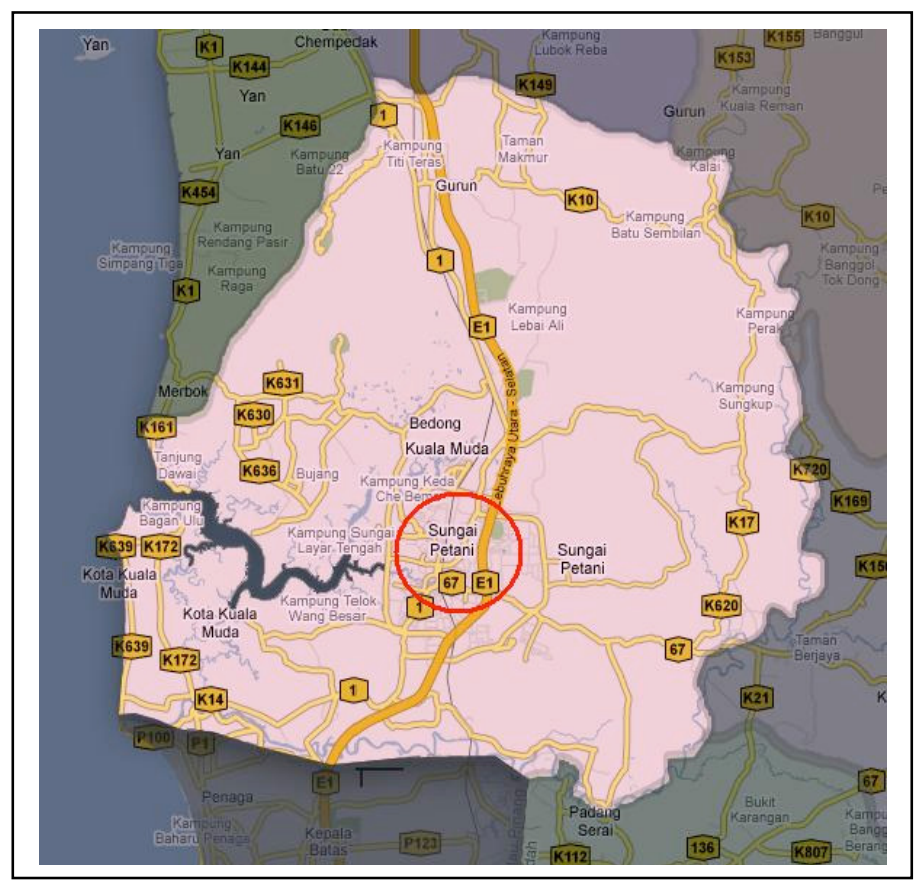

Map 3. Research site: Mukim Sungai Petani, Kuala Muda, Kedah, Malaysia

Map 3 http://images.search.yahoo.com/search/images;ylt=A0S020sNO8xJkYEA880JzbkF?p=kedah+map\&fr=sfp\&ei= utf- $88 \mathrm{x}=$ wrt

\section{Findings and Discussions}

\subsection{Profile of Respondents}

Out of the 200 older persons surveyed the majority (93.0\%) are found to be co-residing with their adult children or relatives, while the remaining $7.0 \%$ respondents are living on their own or only with their spouse (Table 3). 
More specifically, the study found that out of the 200 households surveyed, $7.0 \%$ are of 1-generation family type. A total of $10.0 \%$ are nuclear family of 2-generations, while the extended family consists of $80.0 \% 3$-generation structure and the remaining 3.0\% are 4-generation. This shows that at least in the study area the extended family is still the norm.

Table 3. Family types and structures

\begin{tabular}{lccc}
\hline \multicolumn{1}{c}{ Family type } & Structure & No. & $\%$ \\
\hline Nuclear & & & $\%$ \\
& 1-generation & 14 & 7.0 \\
Extended & 2-generation & 20 & 10.0 \\
& 3-generation & 160 & 80.0 \\
& 4-generation & 6 & 3.0 \\
\hline
\end{tabular}

Source: Field Data 2008

The respondents are mainly between 65-69 years old and are still married or have been married and have children except for one respondent who is unmarried (Table 4). With regard the living arrangement, the influence of filial piety value, respect for elders and the cultural norm of support between parents and children create a strong bond of social and economic commitment between the different generations and translate into a higher proportion of parent-child living arrangement. The data also shows that the aged are overwhelmingly poor. Looking at the income, before retirement or before the age of 60 years the majority $(60.0 \%)$ of the respondents are either unemployed and therefore, have no income or they were earning less than RM500 (approx. USD\$139) a month. After retirement there is an increase in the percentage of the very poor (93.5\%). This fall in the economic status is very distinct and shows that the aged need the support of the family and the state for their economic well being.

Table 4. Profile of aged respondents ( $\mathrm{N}=200)$

\begin{tabular}{|c|c|c|c|}
\hline \multicolumn{2}{|c|}{ Profile } & \multirow{2}{*}{$\begin{array}{c}\text { Numbers } \\
134\end{array}$} & \multirow{2}{*}{$\begin{array}{c}\text { Percent } \\
67.0\end{array}$} \\
\hline Sex & Male & & \\
\hline & Female & 66 & 33.0 \\
\hline \multirow[t]{4}{*}{ Age (years) } & $60-64$ & 42 & 21.0 \\
\hline & $65-69$ & 70 & 35.0 \\
\hline & $70-74$ & 54 & 27.0 \\
\hline & 75 and above & 34 & 17.0 \\
\hline \multirow[t]{3}{*}{ Marital status } & Married & 113 & 56.5 \\
\hline & Divorced/Widowed & 43 & 43.0 \\
\hline & Single & 1 & 0.5 \\
\hline \multirow[t]{6}{*}{ Occupation (sector) } & Public & 14 & 7.0 \\
\hline & Private & 19 & 9.5 \\
\hline & Self-employed & 86 & 43.0 \\
\hline & Entrepreneurs & 19 & 9.5 \\
\hline & Others & 3 & 1.5 \\
\hline & Unemployed/housewives & 59 & 29.5 \\
\hline Income (RM) & No income/ unemployed & 59 & 29.5 \\
\hline \multirow[t]{3}{*}{ (Before retirement) } & Less than 500 & 61 & 30.5 \\
\hline & $500-999$ & 48 & 24.0 \\
\hline & $1000-1499$ & 8 & 4.0 \\
\hline \multirow[t]{3}{*}{ * USD1= RM3.6 } & $1500-1999$ & 1 & 0.5 \\
\hline & 2000-2999 & 5 & 2.5 \\
\hline & 3000 and above & 18 & 9.0 \\
\hline Income (RM) & No income/ unemployed & 152 & 81.7 \\
\hline \multirow[t]{3}{*}{ (After retirement) } & Less than 500 & 22 & 11.8 \\
\hline & $500-999$ & 8 & 4.2 \\
\hline & $1000-1499$ & 2 & 1.1 \\
\hline \multirow[t]{3}{*}{$* \mathrm{USD} 1=\mathrm{RM} 3.6$} & $1500-1999$ & 0 & 0.0 \\
\hline & $2000-2999$ & 0 & 0.0 \\
\hline & 3000 and above & 2 & 1.1 \\
\hline
\end{tabular}

Source: Field Data 2008

As mentioned earlier, 186 co-residing adult second generation were also surveyed. As shown in Table 5, in terms of age they are found to be mainly in the $30 \mathrm{~s}$ and $40 \mathrm{~s}(73.7 \%)$, married $(75.3 \%)$ and have received relatively 
better level of education compared to their parents. Also, different from their parents they are working and involved in other occupations and activities other than those related to agriculture and they are earning relatively better income. However, the majority are only earning between RM500-1999 a month (USD\$139-555) which during this economically trying times would prove to be a heavy burden to care for both the aged and their own family.

Table 5. Profile of co-residing second generation ( $\mathrm{N}=186)$

\begin{tabular}{llcc}
\hline & Profile & Number & Percent \\
\hline Sex & Men & 162 & 87.1 \\
Age (years) & Women & 24 & 12.90 \\
& $20-29$ & 36 & 19.3 \\
& $30-39$ & 84 & 45.2 \\
Marital status & $40-49$ & 53 & 28.5 \\
& 50 and above & 13 & 7.0 \\
& Married & 140 & 75.3 \\
Level of education & Divorced/Widowed & 9 & 4.8 \\
& Single & 37 & 19.9 \\
& No schooling & 1 & 0.5 \\
& Primary school & 4 & 2.1 \\
& Lower secondary school & 9 & 4.8 \\
& Higher secondary school & 153 & 82.2 \\
Occupation (sector) & University/ college & 19 & 10.2 \\
& Public & 40 & 21.5 \\
& Private & 85 & 45.7 \\
& Self-employed & 44 & 23.7 \\
& Entrepreneurs & 10 & 5.4 \\
Income (RM) & Pensioners & 5 & 2.7 \\
$*$ USD1= RM3.6 & 500-999 & 52 & 28.0 \\
& 1000-1499 & 40 & 21.5 \\
& 1500-1999 & 20 & 10.7 \\
& 2000-2999 & 40 & 21.5 \\
& 3000 and above & 34 & 18.3 \\
\hline
\end{tabular}

\section{Source: Field Data 2008}

\subsection{The Aged and the Second Generation}

The study shows that there are various reasons - instrumental, personal, expressive and social - why the first and second generations co-reside. Table 6 shows that among the reasons are the value and belief that it is the duty of the children to care for their aged parents $(50.0 \%)$; that the children are still unmarried $(16.7 \%)$ and therefore should be staying with the parents, especially daughters, and that the children needed a place to stay due to financial constraints and other problems (23.6\%).

Table 6. Reasons for co-residing $(\mathrm{n}=186)$

\begin{tabular}{lcccc}
\hline \multicolumn{1}{c}{ Reasons } & \multicolumn{2}{c}{ Aged parents } & \multicolumn{2}{c}{ Adult children } \\
\cline { 2 - 5 } & Number & $\%$ & Number & $\%$ \\
\hline House near workplace & 13 & 7.0 & - & - \\
$\begin{array}{l}\text { Responsibility of children to care for } \\
\text { parents }\end{array}$ & 94 & 50.5 & 122 & 65.6 \\
Parents' health problems & 2 & 1.1 & - & - \\
Children still unmarried & 31 & 16.7 & 24 & 12.9 \\
Child ask to stay / no place to live & 42 & 23.6 & 11 & 5.9 \\
Widowed & 4 & 2.2 & - & - \\
Divorced & - & - & 1 & 0.5 \\
Very attached to parents & - & - & 28 & 15.0 \\
\hline
\end{tabular}

Source: Field Data 2008 
The co-residing children agreed that caring for the ageing parents is their responsibility (65.6\%). In a more modern, progressive and liberal society unmarried adult children are generally encouraged to move out of the parental household. However, in Malaysia unmarried children, especially daughters, are encouraged to remain in the household except when they have to migrate for reasons of work.

Also, a sense of filial piety is still relatively strong among Malaysian families despite the country undergoing rapid development and transformation and the sense of individualism has begun to make its appearance. The readiness and willingness of both generations to extend their help and support show that the relationship forged is strong and cohesive. This is contrary to the general assumption that rapid industrialisation and modernisation would lead to the breakdown of family values.

With regard the quality of the relationship, the majority of the parents described it as close or very close (89.8\%) while $10.2 \%$ describe the relationship as quite close. None of the 186 co-residing parent(s) perceive their relationship with the children as detached or distant. It can be said that close relationship is fundamental and make co-residence possible and sustainable. Although family size and structure have changed and many adult children have left home, nevertheless the intergenerational relationships and communication can be said to be still relatively intact. Migration has resulted in children breaking out from the family and leaving home especially to take up employment or because of marriage. However, this move does not amount to a breakdown of the family because the extended family is modified and reconstituted through various ways such as making frequent visits home, through phone calls etc. Thus, relationships are sustained and supports continue to be given.

Geographical proximity and frequencies of contact and communication are important influence or determinants of cohesiveness and closeness of relationships. The children express this feeling of closeness and devotion in many different ways, whether they are co-residing or living away from home. As shown in Table 7, these expressions include making frequent visits and telephone calls (93.0\%); attend to parent(s)' basic needs (87.1\%); and confiding in them of problems and issues (87.1\%) as well as provide care during time of illness (67.7\%). The majority of co-residing adult children confirm this. The children who have left home would make a point to return for visits during school holidays, festivals, public holiday family celebrations and such.

Table 7. Various Ways Children Show Their Love and Devotion $(n=186)$

\begin{tabular}{lcc}
\hline \multicolumn{1}{c}{ Ways } & Yes & No \\
\hline Frequent visits and telephone calls & 93.0 & 0.7 \\
Giving gifts & 11.3 & 88.7 \\
Provide all basic needs & 87.1 & 12.9 \\
Confide problems and disturbing issues in & 87.1 & 12.9 \\
parents & & \\
Provide care during illness & 67.7 & 32.3 \\
Go on family holidays together & 44.6 & 55.4 \\
\hline
\end{tabular}

Source: Field Data 2008

As had been mentioned close relationship would facilitate and enable care and support to be more completely and readily transferred. Responsibilities can be willingly carried out without coercion or feelings of obligations as well time could be spent to do activities (domestic, recreation, and entertainment) and to forge and sustain the relationship. As shown in Table 8, the majority of the co-residing generations are aware of their respective responsibilities and are found to be always willing and ready to carry them out. 
Table 8. Frequency and types of relational activities $(\mathrm{n}=186)$

Types of relational activities Aged parents Adult children

\begin{tabular}{|c|c|c|c|c|c|c|}
\hline & Never & Sometimes & Often & Never & Sometimes & Often \\
\hline $\begin{array}{l}\text { There are things that I do } \\
\text { because they are my } \\
\text { responsibilities to the family }\end{array}$ & 0.6 & 43.5 & 55.9 & 1.6 & 45.7 & 52.7 \\
\hline $\begin{array}{l}\text { Family members help to } \\
\text { satisfy my basic needs }\end{array}$ & 1.1 & 37.1 & 61.8 & 1.1 & 41.9 & 57.0 \\
\hline $\begin{array}{l}\text { Family members watch TV } \\
\text { together }\end{array}$ & 2.2 & 51.6 & 46.2 & 0.5 & 51.6 & 47.8 \\
\hline $\begin{array}{l}\text { Family members engage in } \\
\text { recreational activities together }\end{array}$ & 7.5 & 82.3 & 10.2 & 1.6 & 51.1 & 47.3 \\
\hline Help with household chores & 3.2 & 27.4 & 69.3 & 1.1 & 43.0 & 55.9 \\
\hline $\begin{array}{l}\text { Take holiday together with } \\
\text { family members }\end{array}$ & 11.3 & 79.0 & 9.6 & 1.6 & 50.5 & 47.8 \\
\hline $\begin{array}{l}\text { Ask for opinions and advice of } \\
\text { family members when faced } \\
\text { with problems }\end{array}$ & 1.1 & 41.9 & 57.0 & 1.1 & 41.9 & 57.0 \\
\hline
\end{tabular}

Source: Field Data 2008

For relationships to be strong and sustainable, good and effective communication is essential. This is because individual differences can lead to communication breakdown, which in turn would affect relationships. Thus, in order for two individuals to communicate effectively, they need to come to some type of agreement on shared meaning within the communication climate (Miller 2002). With regard to this 'shared meaning' that enables effective communication and common understanding, positive responses from the adult co-residing children regarding 'Confide problems and disturbing issues to parents' (Table 7); 'Ask for opinions and advice of family members when faced with problems' (Table 8); 'Aged help give advice \& supervise growing grandchildren' and 'Help settle family squabbles and conflicts/ ensure family harmony' (Table 9) show close intergenerational relationships as well as effective and good communication. This, in turn has generated reciprocal confidence and trust that enables support and help to be willingly transferred and exchanged.

Helping to manage the children's household and minding the grandchildren are other reasons mentioned by both generations why they co-reside. This shows that there is a two-way flow of help and support given. The aged parents help to care for the grandchildren, manage the household etc. which directly or indirectly contribute towards lessening the burden of the second generation, thus enabling them to concentrate on their jobs as well as attend to their other roles and responsibilities (Table 9). Helping to settle family quarrels and giving advice to grandchildren show that the role of the elderly as pillars of wisdom is still evident.

Table 9. Children's response to why they co-reside with parents $(\mathrm{n}=186)$

\begin{tabular}{lcc}
\hline \multicolumn{1}{c}{ Reasons } & Yes & No \\
\hline $\begin{array}{l}\text { Help to mind the grandchildren when parents } \\
\text { away at work }\end{array}$ & 96.2 & 3.8 \\
$\begin{array}{l}\text { Help manage the household } \\
\begin{array}{l}\text { Help reduce household expenditure - no need } \\
\text { to hire maids }\end{array}\end{array}$ & 100.0 & 0.0 \\
$\begin{array}{l}\text { Help give advice \& supervise growing } \\
\text { grandchildren }\end{array}$ & 99.5 & 97.3 \\
$\begin{array}{l}\text { Help settle family squabbles and conflicts/ } \\
\text { ensure family harmony }\end{array}$ & 100.0 & 0.5 \\
\hline
\end{tabular}

Source: Field Data 2008 


\subsection{Values}

One of the objectives of the study is to see whether there is still in existence a sense of mutual obligations and interests among family members to ensure continuous support and well being of the members in general and the aged in particular. Overall, based on the strength of agreement with statements about intergenerational obligations, it can be concluded that there is support for obligations between parents and their children. In short, there is a general culture of help between family generations although some may be less enthusiastic than others. As shown in Table 10 majority of parents and children agree and acknowledge that there are some things that they do because they are their responsibilities (98-99\%) and that family members help to satisfy basic needs $(98.9 \%)$. It is also generally agreed that taking care of parents is a responsibility of the children (50-66\%). Although only a few of the co-residing children reported that they had asked to stay with their parent(s), the response shows that there exists a sense of obligation on the part of the parent(s) to help the children in times of need.

Table 10. Value statements $(\mathrm{N}=200)$

\begin{tabular}{lcc}
\hline \multicolumn{1}{c}{ Statements } & Aged parents & Adult children \\
& & 65.6 \\
\hline Responsibility of children to care for parents & 99.4 & 98.4 \\
There are things that I do because they are my & & 98.9 \\
responsibilities to the family & 98.9 & 5.9 \\
Family members help to satisfy my basic needs & 23.6 & \\
Child ask to stay / no place to live & &
\end{tabular}

Source: Field Data 2008

\subsection{Aged Living on Their Own}

Most of the aged in the study were found to be residing in two or multi-generation households. However, a total of 14 respondents (11 males and 3 females) were found to be living on their own. Nevertheless, the majority of them do have children. They are aged between 62 and 79 years of age. Their present sources of income come from family members $(14.3 \% \mathrm{n}=14)$, pension $(7.1 \%)$, insurance $(28.6 \%)$, and financial assistance that they receive from the Government Welfare Department (57.1\%).

These aged are living on their own due to various reasons. For older people living on their own is often the result of widowhood or divorce or that the children have left home. The study found that among the reasons are that the children have migrated $(21.4 \% \mathrm{n}=14)$; they prefer to live on their own or only with their spouse $(28.6 \%)$; also the children are unable to care for them due to their personal and financial constraints (14.3\%). However, if given the choice the majority $(71.4 \%)$ indicated that they would rather live with their children due to safety and security reasons; or that they would not feel lonely and there would be someone to care for them.

Living on their own does not always mean that their relationships with the children are strained. In fact the majority had described their relationship with their children to be close or very close $(50.0 \%, \mathrm{n}=14)$ or quite close (35.7\%) while only $14.3 \%$ had described it as detached/ distant (Table 11 ). However, only $50.0 \%$ said that their children do express their care and attention although they may be staying at a distance. These adult children would often visit them or call them on the telephone to enquire about their well being or confide in them their problems; care for them when they are sick and ensure that all their needs are provided. Although they are not staying with any of the children there are still forms of social contact and communication - direct or indirect - to sustain the relationship.

Table 11. Quality of relationship ( $\mathrm{n}=14)$

\begin{tabular}{lccc}
\hline Quality of Relationship & Close & Quite close & Detached/ distant \\
\hline With children & 50.0 & 35.7 & 14.3 \\
Neighbours and friends & 85.7 & 14.3 & - \\
\hline
\end{tabular}

Because they are living on their own, the majority of these aged tend to confide in their friends or neighbours more than they do to their children. A total of 12 elderly interviewed readily admitted that they have close relationship with their friends and neighbours. Also because of the close relationship the majority of those living on their own would often visit their neighbours and friends for company, while $28.6 \%$ would rarely do so mainly due to health reasons, and the desire not to impose. Thus, for those older persons living on their own their social life that depends on the social network and community become increasingly important. 


\subsection{Loneliness}

Although the majority of the aged in the study had described their relationships to the family members, especially their children, as close or very close and that they are content with their present situation $(96.5 \%)$, that does not prevent some of them from experiencing feelings of loneliness from time to time. A total of only $8.5 \%$ of the aged surveyed reported that they do experience the feeling. However, the frequency of the experience differs.

Generally, loneliness is an experience with clear temporal component and not a feeling experienced all the time by an individual. It is a subjective condition and many different situations could give rise to the feeling of loneliness. For example, many respondents reported feeling lonely when the children are too busy and have very little time for them; when they thought about their departed spouses or when they miss their other children and grandchildren.

Findings show that the percentage of older people reporting being lonely or feeling lonely is relatively low. This shows that in the study area majority of the older persons demonstrate a high level of feeling of content with family members, friends and neighbours and therefore, would either experience low level of loneliness or do not experience loneliness at all.

Those who experience the feeling reported that they would try to cope or overcome it in several ways. Among them are that they would go out to meet friends and neighbours; performing prayers; participate in community activities or try to occupy themselves with domestic and other activities. This shows that although external institutions cannot substitute for the family the aged still need their social circle and the community to fill the gap created due to insufficiencies in the family in facing the various challenges brought about by the processes of change and development.

\section{Policy Implications}

Generally, going by the age cut-off of 60 years old that Malaysia has adopted to define the aged, Malaysia has become an aged society by year 2010 when the proportion of aged is over $7.3 \%$. As such, all policies relating to the aged, although already in place, need to be reviewed, improved and amended where necessary. Special attention should be given to certain aspects such as aged care and medical services.

More specifically and based on the study, the family structure has been found to be overwhelmingly extended. However, whether this is a national phenomenon, especially in the Malay majority rural areas would need further study. Nevertheless, this finding for the area is contrary to the general assumption that the family structure has changed to nuclear type. The findings also show that although many members of the rural families have migrated to the urban areas in pursuit of better life and employment, there is no breakdown of the families as relationships and communication are expressed in other ways such as visits, telephone calls, and sending financial remittance home. Improved technology and progressive infrastructure have made this possible.

The data also shows that the respondents are predominantly poor. There is a sharp decrease in the socio-economic status especially upon retirement from work. As such, strategies and programs relating to social safety nets such as provisions for social pension, and productive activities for after retirement need to be formulated or need further strengthening. The productive activities would contribute to active and productive ageing especially for those who are still healthy and want to contribute to community development and nation building.

After the age of 60 years the majority of the aged in the study have been found to have no income-generating activities. As such they have to depend on other family members for economic support. Since the immediate family members who provide direct aged care could also be financially burdened, therefore they should be compensated such as being given subsidy in the form of food vouchers. Admittedly, any system could be open to abuses and, therefore all weaknesses of the system should be studied and addressed.

Considerations should also be given to the setting up of multipurpose centres that are planned, budgeted and professionally run. These centres, funded by the state and/or philanthropists, should be established especially in the rural areas as alternative institution to the traditional care. Various activities and services could be given through these centres such as health care and medical services, social activities etc. At these centres the aged could also receive socio-emotional support as they could interact with other older persons, exchange ideas, discuss problems and provide care and be cared for, thus contributing towards less feelings of loneliness. These multipurpose centres could also include childcare programs. The more healthy and active aged could then be encouraged to help supervise and care for the children. Both the aged and the children could experience positive impacts. While the aged could benefit from active and productive ageing, the children could gain from old-age care and wisdom.

\section{Limitations}

As mentioned earlier, this study was conducted in a mukim in a district in Kedah state. Therefore, the main limitation to this research is that it is restricted to the population that was studied. As such generalisations cannot 
be made for the whole of Kedah state and least of all for the country. Generalisations made are specific to the empirical findings.

\section{Conclusion}

It has always been generally accepted and even shown in some studies that modernisation, urbanisation, industrialisation and migration that accompany the process of development has resulted in physical separation among the different generations of families. Subsequently, this has resulted in a breakdown in the family norms and values of filial piety besides changing the quality and type of intergenerational relationships. However, the study conducted in the rural area of mukim Sungai Petani shows that the intergenerational relationship is still stable and harmonious. The study also shows that the family structure is mainly extended rather than nuclear with the family members exchanging mutual support. In fact family and kinship network have remain an important support network for the families. It is important to note that the family values are still strong even among family members who no longer co-reside in the same household as the aged. For those who have moved out to set up their own households or for reasons of work, support and care are still transferred by other means other than directly. In fact intergenerational relationship and communication are expressed in other forms. Generally, the children show positive and responsible attitudes towards their parents. This is in line with our Malaysian culture that places importance on good and close relationships between generations.

However, from the data it is shown that poverty is a major issue that could impact the well being of the aged, especially in the rural areas. The drastic decline of their socio-economic status renders them vulnerable. Therefore, intervention by the authorities is necessary to address the situation. This is especially important during the economic slowdown, such as being faced by the country at present time, which could result in less transfer and support coming from children due to their own financial constraints.

\section{References}

Bengston, V.L. (1996). Continuities and discontinuities in intergenerational relationship over time. In Bengston V.L. (Ed.), Adulthood and Aging: Research on Continuities and Discontinuities. New York: Springer.

Bengston, V.L., Rosenthal, C.J., \& Burton L.M. (1990). Families and aging: Diversity and heterogeneity. In. Binstock, R.H. and George, L. (Eds.), Handbook of Aging and the Social Sciences ( ${ }^{\text {rd }}$ ed.). New York: Academic Press.

Department of Statistics Malaysia. (1998). Senior Citizens and Population Ageing in Malaysia. Population Census Monograph Series. No. 4. Putrajaya: Department of Statistics Malaysia.

Department of Statistics Malaysia. (2001). Population and Housing Census of Malaysia 2000. Putrajaya: Department of Statistics Malaysia

Kim, H. K., Hisata, M., Kai, I., \& Lee, S. K. (2000). Social support exchange and quality of life among the Korean elderly. Journal of Cross-cultural Gerontology, 15(4), 331-437. http://dx.doi.org/10.1023/A:1006765300028

Kim, I. K., \& Kim, C. S. (2003). Patterns of family support and the quality of life of the elderly. Social Indicators Research, 62(1), 437-454. http://dx.doi.org/10.1023/A:1022617822399

Miller, C. (2002). Communication Theories: Perspectives, Processes and Contexts. Boston: McGraw Hill.

Pillemer, K., Suitor, J.J., Mueller-Johnson, K., Sechrist, J., \& Heidorn, J. (2006). Parent-adult child relations. In Schulz, R. (Ed.), Encyclopaedia of Aging. New York: Macmillan.

Robson, C. (1993). Real World Research. Oxford: Blackwell.

Uhlenberg, P., \& Hammill, B.G. (1998). Frequency of grandparent contact with grandchild sets: Six factors that make a difference. The Gerontologist, 38, 276-285. http://dx.doi.org/10.1093/geront/38.3.276

Vebrugge, L.M., \& Chan, A. (2008). Giving help in return: Family reciprocity by older Singaporeans. Ageing and Society, 28(1), 5-34.

\section{Notes}

Note 1. The terms 'elderly', 'aged' and 'older persons' used in this article refer to the same category of people aged 60 years and above. The terms are used interchangeably throughout the article.

Note 2. In Malaysia the population census is conducted every 10 years. The latest census was conducted in 2010, but the findings are still inaccessible. As such the 2000 census published in 2001 is used as a source of reference.

Note 3. In Malaysia, those aged 60 years and above are officially defined as 'old', similar to the definition adopted by the United Nations.

Note 4. Malaysia is a federation of 13 states and 3 federal territories. For administrative purposes each state is divided into a number of districts. Each district is then further divided into a number of mukim or sub-districts. 